\title{
reviews
}

\section{Sorting the muddle in the Middle}

W. W. Bishop

After the Australopithecines: Stratigraphy, Ecology, and Culture Change in the Middle Pleistocene. (World Anthropology.) Edited by Karl W. Butzer and Glynn Ll. Isaac. Pp. $x v+911$. (Mouton: The Hague and Paris, 1975.) (Distributed in US and Canada by Aldine: Chicago.) Dutch Guilders 127.50.

THIS is a most timely review of work on the span of the Quaternary, dubbed broadly Middle Pleistocene, younger than the australopithecine-bearing strata that have been calibrated by potassium-argon dating. The period is terminated by the advent of the Later Pleistocene which is followed by the lower limit of radiocarbon dating at $\pm 50,000$ yr b.p. The continental deposits in 'the middle' represent a period when reliable dates from sources independent of the fossil faunas or artefact assemblages for which an age is sought are extremely scarce. Lithological comparisons are rendered difficult by isolation of the sedimentary basins and the parochial nature of the deposits. Attempts have been made to use climatic change as the vehicle for correlation, but these are largely unsatisfactory until the Last Interglacial (Ipswichian-Eemian) denotes the onset of the Later Pleistocene.

Middle Pleistocene continental stratigraphy in the Old World is therefore a muddle which this volume does a great deal to clarify by isolating the problems and suggesting solutions. I must carp a little at the length, not to say verbosity, of several of the contributions. Thus 21 papers amount to 887 pages, including excellent black and white illustrations. This yields an average of 42 pages per contributor and is the reason that for most students of the Quaternary, from the undergraduate to professorial grade, this volume priced at $£ 26$ sterling per copy, sadly seems destined almost solely for library shelves.

With this caveat it must be noted that the papers have been carefully selected by the editors and the scope of the book is broad but balanced. The geological contributions include the record of deep sea cores (Shackleton), the Mediterranean littoral (Butzer), volcanics of the Massif Central (Bout), European Loess stratigraphy (Kukla) and sediments of East Anglia (Glad- felter). On this substratum, interglacial correlation is discussed by Turner, and various aspects of mammalian palaeontology by Kahlke, Janossy, Jaeger and Maglio, respectively.

The lithic industries of Africa, the Middle East and Europe are then placed into the stratigraphic framework by Mary Leakey, Isaac, Deacon, BarYosef, Clark, Freeman and de Lumley. Finally, Pilbeam reviews the fossil evidence for Middle Pleistocene toolmaking hominids.

The volume is an essential reference book for all workers involved in the problems of the Middle Pleistocene. Space does not permit an analysis of the papers beyond noting that they provide the most up-to-date statement in this field. The papers were revised and submitted to the editors after a conference organised in July 1973 by the Wenner-Gren Foundation for Anthropological Research at Burg Wartenstein, Austria.

The meat of the conference and the conclusions arising from this meeting between workers in different disciplines are provided in two short concluding chapters by Butzer on the Geology and Ecology (18pp) and Isaac on the Archaeology and Anthropology (14pp), together with two Appendices containing correlation charts and the recommendations of the meeting.

The most potent wine is kept until the end of the book (pp901-903). It was recommended unanimously by the conference that the lower boundary of the Middle Pleistocene be defined as the junction between the Matuyama Reversed Epoch and the Brunhes Normal Epoch of the palaeomagnetic reversal chronology (that is at about $0.7 \mathrm{Myr}$ ). Magnetostratigraphy is still at an early stage of development but the reasons for choosing "this unique global criterion" include: the difficulty experienced in trying to apply other methods; its application to both marine and continental sediments; the fact that it can be established in many existing litho-stratigraphic units; and in some areas there is a good fit with the existing local placement of the boundary. The fact that a major change from the current location of the boundary would be necessary in some other areas points the need to use some global parameter.

The proposed upper boundary is the beginning of the marine transgression associated with the onset of the Last Interglacial. Although the inadequacy of this boundary is recognised it seems to be the best available at present. It is to be hoped that those concerned with codes of stratigraphic nomenclature will recognise the value of the proposed palaeomagnetic reversal boundary for the lower limit and that stratigraphic connoisseurs will find this new wine acceptable to the international palate.

W. W. Bishop is Professor and Head of the Department of Geology at Queen Mary College, University of London, $U K$. His research interests for the past 20 years have centred on the geological background to fossil man in East A frica.

\section{Controversial morphometrics}

Uniqueness and Diversity in Human Evolution: Morphometric Studies of Australopithecines. By Charles E. Oxnard. Pp. viii + 133. (University of Chicago: Chicago and London, 1975.) $£ 9.00$.

IN spite of caveats about the tentative nature of the results in this volume Oxnard has thrown down the gauntlet firmly at the feet of hominid paleontologists. Implicitly throughout much of the book, and explicitly in the final chapter, he claims that the Australopithecines (including Homo habilis and 'Homo africanus') should be formally excluded from any ancestral relationship to man. The basis for this view is that morphometric studies he cites show them not only to be unique but also, in several computer analyses their nearest analogues are orang-utans, specialised Asian apes. The test is whether Oxnard's book contains sufficiently cogent evidence for such a bold view.

The book is in three sections. The first two chapters consist of a theoretical discussion about how best structure and behaviour can be equated, a review of discriminant analysis and methods for displaying the results, and a review of locomotor classification. 